EESTI NSV TEADUSTE AKADEEMIA TOIMETISED. XII KÖIDE

FOOSIKA-MATEMAATIKA. JA TEHNIKATEADUSTE SEERIA. 1963, NR. 3

ИЗВЕСТИЯ АКАДЕМИИ НАУК ЭСТОНСКОЙ ССР. ТОМ ХІІ

СЕРИЯ ФИЗИКО-МАТЕМАТИЧЕСКИХ И ТЕХНИЧЕСКИХ НАУК. 1963, № 3

\title{
SUNTEESE HEKSAKLOORTSUKKLOPENTADIEENIST
}

\section{H. RANG}

Heksakloortsüklopentadieenist toodetakse insektitsiide - kloorindaani, heptakloori, aldriini, dieldriini, isodriini, endriini ja tiodaani. Peale nende on heksakloortsüklopentadieenist sünteesitud kõrge kuumuskindlusega vaike, fungitsiide, nematotsiide, herbitsiide, taimekasvuregulaatoreid, plastifikaatoreid jne. Heksakloortsüklopentadieeni ennast on võimalik toota ka põlevkivi gaasbensiini penteen-pentaan fraktsioonist $70 \%$-lise saagisega [1].

Uute ühendite sünteesimiseks. heksakloortsüklopentadieenist on kasutatud viimase omadust reageerida dieenofiilidega Dielsi-Alderi järgi. Seoses sellega pakub huvi uurida kohalikus tooraines esinevate dieenofiilide reaktsioone heksakloortsüklopentadieeniga. Pōlevkivi vedelates produktides leidub dieenofiilidest alkeene, alkadieene, tsükleene ja tsüklodieene. Kõige enam neist esineb juba uuritud ja kasutamiseks mõeldavas osas normaalseid 1-alkeene $\left[{ }^{2}{ }^{3}\right]$. Alkeenid reageerivad heksakloortsüklopentadieeniga järgmiselt:

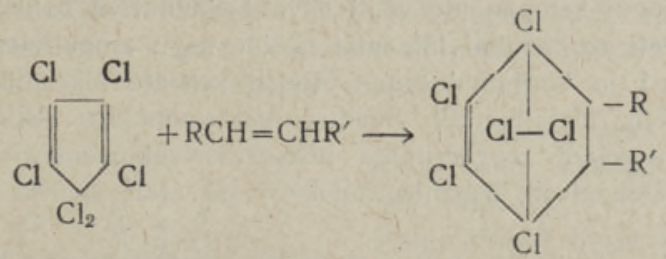

Seni on neid ühendeid sünteesinud mitmed keemikud $[4,5,6,7,8$, kelle töö tulemused esitatakse tabelis 1 .

Tabel 1 .

Heksaklooralküülbitsüklohepteenide süntees

\begin{tabular}{l|c|c|c|c}
\hline Alkeen (dieenofiil) & $\begin{array}{c}\text { Saagis, } \\
\%\end{array}$ & $\begin{array}{c}\text { Keemistemperatuur, } \\
{ }^{\circ} \mathrm{C} / \text { tor }\end{array}$ & $\begin{array}{c}\text { Murdumis- } \\
\text { näitaja, } \\
n_{D}^{20}\end{array}$ & Uurimus \\
\hline Penteen-1 & 21 & $138-142 / 2$ & - & {$\left[{ }^{4}\right]$} \\
Penteen-2 & 71 & $149-150 / 8$ & 1,5365 & {$[8]$} \\
2-metüülbuteen-3 & 33 & $140-144 / 3-5$ & - & {$[4]$} \\
Hekseen-1 & 32 & $150-154 / 3$ & - & {$[4]$} \\
$\# ”$ & 55 & $147-150 / 2$ & - & {$[4]$} \\
Hepteen-1 & 60 & $145-148 / 1,8$ & - & {$[0]$} \\
Okteen-1 & 65 & $149-151 / 3$ & 1,5309 & {$[5]$} \\
Detseen-1 & 50 & $150-152 / 0,7$ & - & {$[6]$} \\
Oktadetseen-1 & 54 & $152-155 / 0,7$ & - & {$[4]$} \\
& 86 & $152-153 / 3$ & 1,5235 & {$[5]$} \\
& 86 & $184-186 / 2,5$ & 1,5180 & {$[8]$} \\
& 97 & & - & {$[5]$}
\end{tabular}


Saadud reaktsiooniprodukte pole lähemalt iseloomustatud. Saagised on küllaltki madalad; pole uuritud reaktsiooni aja ega temperatuuri mõju saagisele. Saadud produktid olid helekollased viskoossed lōhnata vedelikud $[4,5,6,7]$.

Käesolevas töös kasutati lähtematerjalina heksakloortsüklopentadieeni $\left(d_{4}^{20} 1,7107\right.$; $n_{D}^{20} 1,5649$; keemistemperatuur $94^{\circ} \mathrm{C} / 5$ torri) ja alkoholidest sünteesitud alkeene $\left[{ }^{9}, 10\right]$. Viimaste iseloomustus esitatakse tabelis 2. Alkeenide puhtus määrati nii gaasvedelikkromatograafiliselt kui ka infrapunaste spektrite pōhjal.

Tabel 2

Alkoholidest sünteesitud alkeenide iseloomustus

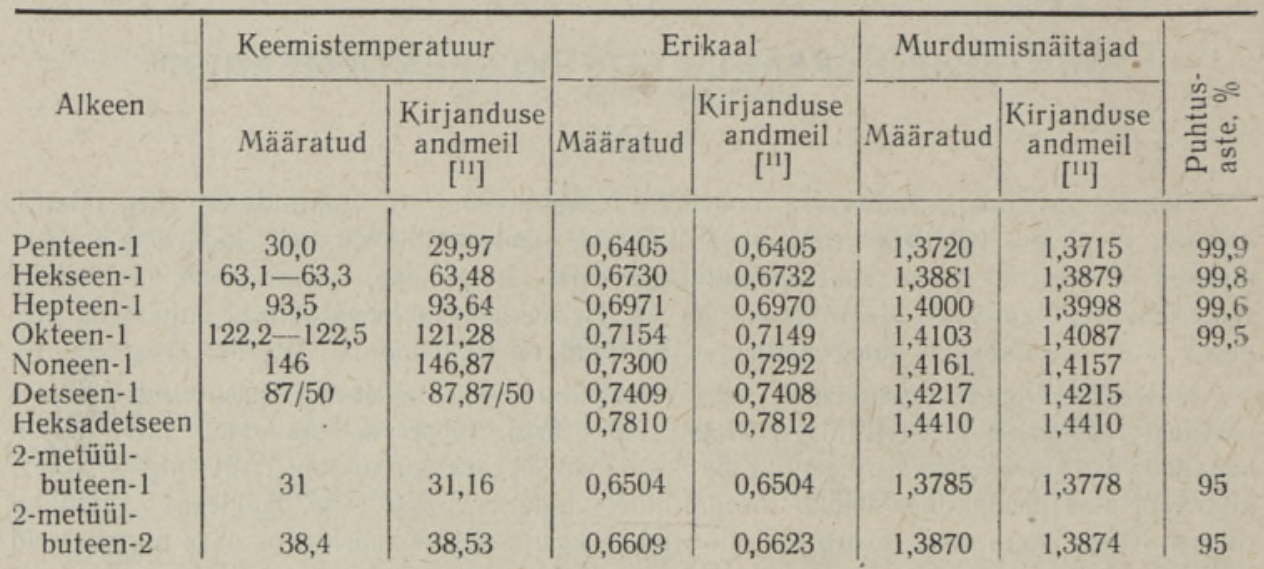

Mõlemaid reaktsiooni komponente võeti ekvimolekulaarses vahekorras. Penteenide ja hekseen-1 puhul joodeti reaktsiooni lähtematerjalide segu ampullidesse, mida soojendati kaitsekestas. Hepteen-1 ja kôrgemal temperatuuril keevate alkeenidega viidi reaktsioon läbi püstjahutiga kolvis metallvannil. Saadud reaktsioonisegu rektifitseeriti vaakuumis, kusjuures eeljooksuna saadi reageerimata heksakloortsüklopentadieen ja edasi vastav heksaklooralküülbitsüklohepteen. Destilleerimiskolbi jäi alati vähene hulk tumedat tõrvasarnast ainet.

Optimaalse reaktsiooniaja ja -temperatuuri väljaselgitamiseks korraldati terve rida katseid. Heksaklooralküülbitsüklohepteeni saagis arvutati reaktsiooni segu broomarvu ja destillatsioonisaaduste hulga järgi. Katsete tulemused esitatakse tabelites 3 ja 4 .

Tabel 3

Tabel 4

Reaktsiooni temperatuuri mõju heksakloorpropüülbitsüklohepteeni saagisele

\begin{tabular}{c|c}
\hline $\begin{array}{c}\text { Temperatuur, } \\
{ }^{\circ} \mathrm{C}\end{array}$ & $\begin{array}{c}\text { Saagis, } \\
\%\end{array}$ \\
\hline 100 & 42 \\
125 & 71 \\
150 & 80 \\
175 & 76
\end{tabular}

Kōigis katsetes kestis reaktsioon 5 tundi.
Reaktsiooni aja mōju heksakloorpropüül-heksüül- ja -oktüülbitsüklohepteenide saagisele

\begin{tabular}{c|c|c|c}
\hline \multirow{2}{*}{$\begin{array}{c}\text { Aeg } \\
\text { tundides }\end{array}$} & \multicolumn{3}{|c}{ Saagis, \% } \\
\cline { 2 - 4 } & -propüül- & -heksüül- & -oktüül- \\
\hline \multirow{2}{*}{5} & 80 & 77 & 78 \\
8 & 90 & 89 & 85 \\
10 & 90 & 88 & 90 \\
30 & 92 & 93 & 90
\end{tabular}

Reaktsiooni temperatuur kõigis katsetes oli $150^{\circ}$.

Nagu nähtub toodud andmeist, võib optimaalseks reaktsiooni temperatuuriks pidada $150^{\circ}$. Saagise languse pōhjuseks kõrgemal temperatuuril on tõenäoliselt olefiinide polümerisatsioon või oksüdatsioon enne dieensünteesi. Seda tõestab ka reaktsioonisegu tume- 
dam värvus ja destillatsioonijäägi suurem hulk. Optimaalne reaktsiooni aeg kōigi normaalsete 1 -alkeenide puhul on 8-10 tundi.

Raske on pōhjendada mōnede autorite $\left[{ }^{4}, 5,6\right]$ küllalt madalaid saagiseid (vt. tab, 1). Tōenäoliselt oli reaktsooni aeg nende katsetes liiga lühike.

Et välja selgitada alkeeni kaksiksideme lähedal asuva metüülrühma mõju reaktsiooni kiirusele dieensünteesil heksakloortsüklopentadieeniga, korraldati rida katseid penteen-1, 2-metüülbuteen-1 ja 2-metüülbuteen-2-ga, kus määrati heksaklooralküülbitsüklohepteeni saagise olenevus reaktsiooni ajast. Katsete tulemused esitatakse joonisel 1 .

Nagu joonisel 1 toodud kõveratest ilmneb, on reaktsiooni kiirus seda väiksem, mida lähemal asub alkeeni kõrvalahela metüülrühm kaksiksidemele. Destilleerimisel saadi erineva tumedusastmega helekollaseid heksaklooralküülbitsüklohepteene. Seepärast peeti vajalikuks neid veel täiendavalt puhastada. Selleks kasutati eelnevalt töödeldud silikageeli $\mathrm{KCM}\left[{ }^{12}\right]$ ja aktiveeritud sütt. Silikageel asetati poorse pōhjaga silindrilisse lehtrisse (läbimôoóduga $2 \mathrm{~cm}$ ). Sellele valati puhastatav hek-

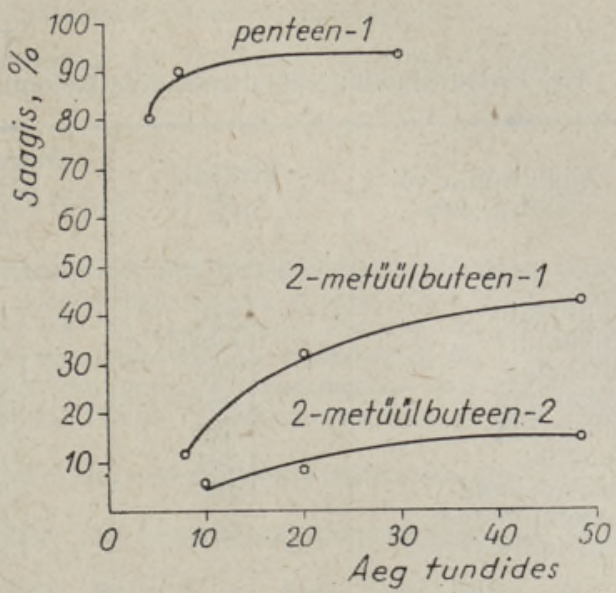

Joon. 1. Penteenide ja heksakloortsüklopentadieeni liitumisproduktide saagiste olenevus reaktsiooni kestusest. saklooralküülbitsüklohepteen. Pärast heksaklooralküülbitsüklohepteeni nōrgumist läbi silikageeli pesti teda süsiniktetrakloriidiga. Nii läbi silikageeli nõrgunud kui ka süsiniktetrakloriidi-lahusest pärast lahusti aurutamist saadud heksaklooralküülbitsüklohepteen olid värvusetud ja nende füüsikalised konstandid olid samased.

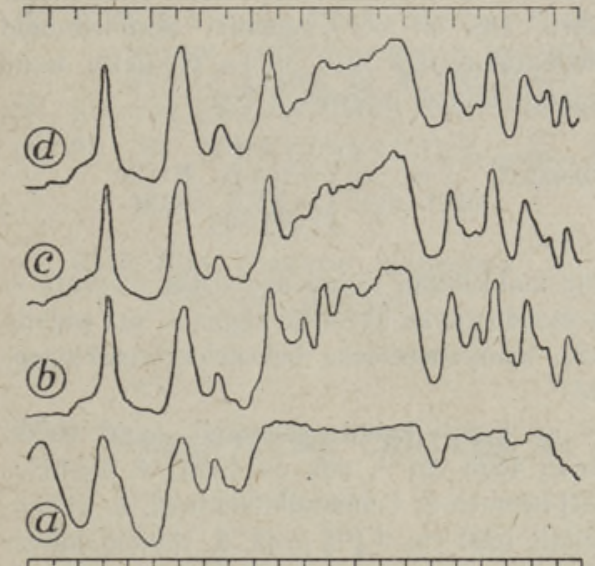

$1700 \quad 1600 \quad 15007400 \quad 1300120010001000900800700 \mathrm{~cm}^{-1}$

Joon. 2. Infrapunased spektrid: $a-$ heksakloorbutüülbitsüklohepteenist eraldatud lisand; $b$ - heksakloorbutüülbitsüklohepteen; $c$ heksaklooroktüülbitsüklohepteen; $d-$ heksakloortsüklopentadieeni ja heksadetseeni liitumisprodukt.

Järgnevalt pesti silikageeli veevaba metanooliga. Saadud kollast lahust aurutati vaakuumis ( 20 torri jääkrōhku) $20^{\circ}$ temperatuuril. Eraldatud heksaklooralküälbitsüklohepteeni lisand oli pruun viskoosne vedelik. Selle iseloomustamiseks spektrometreeriti kõnesolevaid lisandeid infrapunase spektromeetriga ИКС-14 (kasutati naatriumkloriidprismat, kihi paksus $0,03 \mathrm{~mm}$ ). Joonisel 2 on esitatud heksakloorbutüülbitsüklohepteenist eraldatud lisandi spekter.

Eespool kirjeldatud meetodil puhastati kōiki sünteesitud heksaklooralküülbitsüklohepteene. Optimaalseks silikageeli ja heksaklooralküülbitsüklohepteeni vahekorraks oli $1: 1$. Heksaklooralküülbitsüklohepteenides leidus ülalnimetatud lisandit kuni $1 \%$. Puhastamiseks sobis ka aktiveeritud süsi, mida võeti samas vahekorras silikageeliga.

Arvestades lähtematerjalide küllaltki suurt puhtust, sünteesi käiku, täiendavat puhastust, määratud ning arvutatud moolkaalu ja kloorisisalduse ühtelangevust, vōib oletada, et saadud heksaklooralküülbitsüklohepteenid on puhtad ühendid. Nad kōik on viskoossed värvuseta ja lōhnata vedelikud. Nende paremaks iseloomustamiseks võeti 
kôigist normaalse alküülrühmaga ühenditest infrapunased spektrid spektromeetril ИKC-14 (naatriumkloriidprisma, kihi paksus $0,03 \mathrm{~mm}$ ). Mõned spektrid esitatakse joonisel 2. Sünteesitud ühendite iseloomustus antakse tabelis 5 .

Nimetatud ühendite spektreid ega nende lähemat iseloomustust pole seni kirjanduses avaldatud. 1, 2, 3, 4, 7, 7-heksakloor-5-heptüül-bitsüklohepteen-2 sünteesiti esmakordselt.

Ka heksadetseenist, 2-metüülbu-

Tabel 5 teen-1-st ja 2-metüülbuteen-2-st

Heksaklooralküülbitsüklohepteenide iseloomustus saadi esmakordselt heksaklooral-

\begin{tabular}{|c|c|c|c|}
\hline $\begin{array}{l}\text { Alküülrühm või } \\
\text { lähtealkeen }\end{array}$ & $\begin{array}{l}\text { Erikaal, } \\
\qquad d_{4}^{20}\end{array}$ & $\begin{array}{l}\text { Murdumis- } \\
\text { näitaja, } \\
n_{D}^{20}\end{array}$ & $\begin{array}{l}\text { terjali (vastava alkeeni) mittekül } \\
\text { laldase puhtuse tōttu pole võimalik } \\
\text { saadud produkte pidada individual } \\
\text {-seiks ühendeiks. Reaktsiooni tingi }\end{array}$ \\
\hline $\begin{array}{l}\text { 5-propüül- } \\
\text { 5-butüül- } \\
\text { 5-amüül- } \\
\text { 5-heksüül- } \\
\text { 5-heptüül- } \\
\text { 5-oktüül- } \\
\text { leksadetseen } \\
\text {-metüülbuteen-1 } \\
\text {-metüülbuteen-2 }\end{array}$ & $\begin{array}{l}1,476 \\
1,428 \\
1,397 \\
1,364 \\
1,326 \\
1,304 \\
1,188\end{array}$ & $\begin{array}{l}1,5361 \\
1,5309 \\
1,5271 \\
1,5235 \\
1,5210 \\
1,5180 \\
1,5074 \\
1,5426 \\
1,5432\end{array}$ & $\begin{array}{l}\text { muste muutmisega püüti saada puh- } \\
\text { taid (värviliste lisanditeta) hek } \\
\text { saklooralküülbitsüklohepteene. Kin- } \\
\text { nijoodetud ampullides, } \mathrm{CO}_{2} \text {-atmo } \\
\text { sfääris värskelt rektifitseeritud } \\
\text { alkeenidest önnestuski hüdrokinoon } \\
\text { manulusel saada pärast destilleeri } \\
\text { mist peaaegu värvusetuid hek } \\
\text { saklooralküülbitsüklohepteene. }\end{array}$ \\
\hline
\end{tabular}

Varem sünteesitud penteen-1, detseen-1 $\left.{ }^{[}\right]$, hekseen-1 ja okteen-1 $\left[^{5}\right]$ ning heksakloortsüklopentadieeni liitumisproduktide murdumisnäitajad langevad hästi kokku antud töös sünteesitud ühendite konstantidega. Kuigi heksadetseeni konstandid on lähedased kirjanduses esitatutele, puudusid kahjuks vahendid heksadetseeni puhtuse kontrollimiseks, mistōttu antud töös ei käsitleta seda ja sellest saadud liitumisprodukti puhaste ühenditena.

Heksaklooralküülbitsüklohepteenidest eraldatud lisandite spektrites esinevad pōhiliselt samad maksimumid mis vastavail heksaklooralküülbitsüklohepteenidelgi, välja arvatud suur maksimum lainearvu piirkonnas $1702-1723 \mathrm{~cm}^{-1}$, mis viitab karbonüülsele sidemele [13] ja seega asjaolule, et üks reaktsiooni komponent on oksüdeerunud. Kuna heksakloortsüklopentadieen ōhuhapniku toimel ei oksüdeeru, siis. on meil tegemist oksüdeerunud olefiiniga, mis on reageerinud heksakloortsüklopentadieeniga. See on ka vōimalik, kuna teatavasti alkeeni oksüdeerumine kulgeb ōhuhapniku toimel järgmiselt $\left[{ }^{14}\right]$ :

$$
-\mathrm{C}=\mathrm{C}-\mathrm{C}-+\mathrm{O}_{2} \longrightarrow-\underset{\mathrm{O}-\mathrm{O}-\mathrm{H}}{\mathrm{C}=\mathrm{C}-\mathrm{C}-}
$$

880 ja $1030 \mathrm{~cm}^{-1}$ puhul peroksüüdse sideme maksimumi antud spektrites määrata ei õnnestunud. Peroksüüdide esinemist nn. lisandit moodustavas ühendite segus ei saa pidada vōimalikuks. Tõenäoliselt on lisandis peamisteks komponentideks heksakloorbitsüklohepteenset tsüklit sisaldavad karbonüülsed ühendid.

Heksaklooralküülbitsüklohepteenide spektrid on kujult kaunis sarnased, nagu vōibki oletada. Iseloomulikuks maksimumiks võib pidada $1595 \mathrm{~cm}^{-1}$, mis on tingitud bitsüklohepteeni kaksiksidemest. 2-metüülbitsüklo-[2, 2, 1]-hepteen-2, 1-metüülbitsüklo-[2, 2, 1]-hepteen-2 puhul on see $1610-1620 \mathrm{~cm}^{-1}\left[{ }^{15}\right]$, dieldriinil $1600 \mathrm{~cm}^{-1}\left[{ }^{15}\right]$ ja $[2,2,1]$-bitsüklohepteen-5-üül-2-etüülsulfoonil $1570 \mathrm{~cm}^{-1}\left[{ }^{16}\right]$.

\section{Kokkuvõtt}

1. Sünteesiti 1, 2, 3, 4, 7, 7-heksakloor-5-propüül, -5-butüül-, -5-amüül-, -5-heksüü!-, -5-heptüül-, -5-oktüül- $[2,2,1]$-bitsüklohepteen-2 ja iseloomustati neid esmakordselt lähemalt füüsikaliste konstantidega ning infrapunaste spektritega. Esmakordselt sünteesiti 1, 2, 3, 4, 7, 7-heksakloor-5-heptüül-bitsüklohepteen-2. 'Ka heksadetseenist, 2-metüülbuteen-1-st ja 2-metüülbuteen-2-st saadi heksaklooralküülbitsüklohepteenid esmakordselt. 
2. Selgitati heksaklooralküülbitsüklohepteenide sünteesi optimaalsed tingimused ja näidati, et normaalseist alkeenidest saab neid sünteesida 90-93\%-lise saagisega.

3. Näidati, et Dielsi-Alderi reaktsiooni kiirus heksakloortsüklopentadiceni ja alkeeni vahel väheneb tunduvalt, kui alkeeni kaksiksideme lähedal asuvad külgmised metüülrühmad.

4. Töötati välja meetod heksaklooralküülbitsüklohepteenide puhastamiseks.

5. Näidati, et heksaklooralküülbitsüklohepteenid on värvuseta ja lōhnata viskoossed vedelikud.

\section{K I R J A N D S}

1. Х. Р ан г. Синтез гексахлорциклопентадиена из пентенпентановых фракций сланцевых ғазбензинов. Изв. АН ЭССР, Серия физ.-матем. и техн. наук, 2, 90, 1962.

2. О. Г. Эй зен, С. А. Р а нг, Х. А. Р а нг. О химическом составе легких фракций сланцевого бензина. Химия и технология топлив и масел, 5, № $3,8,1960$.

3. О. Г. Э й зен, С. А. Р а нг. О химическом составе олефиновых углеводородов сланцевой смолы. Сб. Горючие сланцы. Химия и технология, вып. 4. Эст. ГИЗ, 1961.

4. C. B e r g e r, O, B e cher. Umsetzung von Hexachlorcyclopentadien mit Olefinen. Z. Naturforsch., 9b, 10, 684, 1954.

5. E. K. Fie I d s. Reactions of monoolefines and hexachlorocyclopentadiene. J. Amer. Chem. Soc., 76, 2709, 1954.

6. R. Riemschneider, A. Kühnl. Mitt. Phys. Chem. Inst. Univ. Berlin, R 11, 1947.

7. R. Riem schneider, A. Kühnl. Monatsschr. Chem., $86,879,1955$.

8. L. S chmerling. US patent 2881223 (7. apr. 1959); C. A. 17013, 1959.

9. F. A s inger. Chem. Ber., 75, 1247, 1942.

10. F. A s i n g er. Chem. Ber., 75, 1251, 1942.

11. Р. Д. Оболенцев. Химические константы углеводородов жидких топлив и масел. М.-Л., 1958.

12. А. В. Топчиев, И. А. Мусаев, Э. Х. Исхакова, А. Н. Кислинский, Г. Д. Гальп ерн. Химия и технология топлива, $12,1,1956$.

13. L. J. B ell a m y. The Infra-Red Spectra of Complex Molecules. New York, 1958.

14. Д. Г. Кнорре, 3. К. Май зус, Л. К. Обухов а, Н. М. Эмануэль. Современное представление о механизме окисления углеводородов в жидкой фазе. Успехи химии, 26, 4, 416, 1957.

15. Infrared Spectral. Data. Amer. Pet. Inst. Research Project, 44.

16. М. Ф. Шостаковский, Е. Н. Прилежаева, В. А. Азовская, Г. В. Ди м и тр и в а. Исследование в области сульфонов и сульфоксидов. ЖОХ. ХXX, 4, 1123, 1960.
Eesti NSV Teaduste Akadeemia
Keemia Instituut
Saabus toimetusse
25. XII 1962

\section{НЕКОТОРЫЕ СИНТЕЗЫ ИЗ ГЕКСАХЛОРЦИКЛОПЕНТАДИЕНА}

\section{Х. Ранг}

\section{Резюме}

Синтезирован целый ряд гексахлоралкилбициклогептенов из гексахлорциклопентадиена и нормальных 1-алкенов, а также 2-метилбутенов и выяснены оптимальные условия их синтеза, при которых выход гексахлоралкилбициклогептенов из нормальных 1-алкенов составлял 90-93\%. Впервые были синтезированы 1, 2, 3, 4, 7, 7-гексахлор-5-гептил-[2,2,1]-бициклогептен-2, а также гексахлоралкилбициклогептены из гексадецена, 2-метилбутена-1 и 2-метнлбутена-2.

В инфракрасных спектрах гексахлоралкилбициклогептенов имеется максимум $1595 \mathrm{~cm}^{-1}$, характеризующий двойную связь бициклогептенов.

Изучено влияние строения алкенов на их реакщионную способность в реакции с гексахлорциклопентадиеном и показано, что наиболее реакционноспособными являются 
нормальные алкены. Наличие четвертичных углеродных атомов в соседстве с двойной связью или у двойной связи алкена понижает реакционную способность олефина.

Выработан метод для очистки гексахлоралкилбициклогептенов и показано, что в продуктах синтеза могут присутствовать коричневые примеси, которые являются карбонильными соединениями, содержащими гексахлорбициклогептеновую группу. Последние соединения образуются из окисленного алкена и гексахлорциклопентадиена.

Все синтезированные гексахлоралкилбициклогептены были бесцветные вязкие жидкости, не имеющие запаха.

Институт химии

Академии наук Эстонской ССP

\section{Поступила в редакцию}

25. XII 1962

\section{SOME PREPARATIONS FROM HEXACHLOROCYCLOPENTADIENE}

\section{H. Rang \\ Summary}

There were synthesized a number of hexachloroalkylbicycloheptenes from hexachlorocyclopentadiene and alkenes. Optimal conditions of the preparations were determined. From n-alkenes, hexachlorobicycloheptenes yield $90-93 \%$. 1, 2, 3, 4, 7, 7-hexachloro-5-heptyl$[2,2,1]$-bicyclohept-2-ene and hexachlorobicycloheptenes from hexadecene, 2-methylbut1 -ene and 2-methylbut-2-ene were synthesized first.

To determine the reaction rates of hexachlorocyclopentadiene and alkenes, three pentenes and diene were reacted. The reaction rates were found to decrease in the following order: pent-1-ene $>2$-methylbut-1-ene $>2$-methylbut-2-ene.

A method for purifying hexachlorobicycloheptenes was examined. The purified hexachlorobicycloheptenes were viscous, colourless, and odourless liquids.

The specific maximum of hexachlorobicycloheptenes in the infrared spectra at 1595 $\mathrm{cm}^{-1}$ is the double bond maximum of bicycloheptene.

Academy of Sciences of the Estonian S.S.R.,

Received Institute of Chemistry 